\title{
Microcephalic osteodysplastic dysplasia, Saul-Wilson type
}

INSERM

\section{Source}

INSERM. (1999). Orphanet: an online rare disease and orphan drug data base.

Microcephalic osteodysplastic dysplasia, Saul-Wilson type. ORPHA:85172

Microcephalic osteodysplastic dysplasia, Saul-Wilson type is a skeletal dysplasia

characterized by a distinct facial phenotype, short stature, brachydactyly, clubfoot deformities, cataracts, and microcephaly. It has been described in four patients. Facial features include frontal bossing with a depression over the metopic suture, a narrow nasal root with a beaked nose, and midfacial hypoplasia with prominent eyes.

Characteristic radiog raphic findings are observed (irregularities of the vertebral bodies, hypoplasia of the odontoid process, short phalanges, coning several epiphyses etc.). 